\title{
Retrospective Post-mortem SARS-CoV-2 RT-PCR of Autopsies with COVID-19-Suggestive Pathology Supports the Absence of Lethal Community Spread in Basel, Switzerland, before February 2020
}

\author{
Jasmin Dionne Haslbauer ${ }^{a}$ Valeria Perrina ${ }^{a}$ Matthias Matter ${ }^{a} \quad$ Athanassios Dellas $^{b}$ \\ Michael J. Mihatsch ${ }^{a}$ Alexandar Tzankova \\ a Pathology, Institute of Medical Genetics and Pathology, University Hospital Basel, University of Basel, \\ Basel, Switzerland; 'bepartment of Clinical Research, University Hospital Basel, University of Basel, \\ Basel, Switzerland
}

\section{Keywords}

Autopsy - Infectious pathology · COVID-19 - SARS-CoV-2 .

Diffuse alveolar damage

\begin{abstract}
Introduction: Coronavirus disease 2019 (COVID-19) caused by severe acute respiratory syndrome coronavirus 2 (SARSCoV-2) has rapidly spread around the world. While the first case was recorded in Hubei in December 2019, the extent of early community spread in Central Europe before this period is unknown. A high proportion of asymptomatic cases and undocumented infections, high transmissibility, and phylogenetic genomic diversity have engendered the controversial possibility of early international community spread of SARS-CoV-2 before its emergence in China. Methods: To assess the early presence of lethal COVID-19 in Switzerland, we retrospectively performed an analysis of deaths at University Hospital Basel between October 2019 and February 2020 $(n=310)$, comparing the incidence of clinical causes of death with March $2020(n=72)$, the month during which the first lethal COVID-19 cases in Basel were reported. Trends of COVID-19-suggestive sequelae, such as bronchopneumonia with organization, acute respiratory distress syndrome (ARDS), or pulmonary embolisms (PE) were evaluated. In cas-
\end{abstract}

es where autopsy was performed $(n=71)$, analogous analyses were conducted on the cause of death and pulmonary histological findings. Eight cases with a COVID-19-suggestive clinical history and histopathology between October 2019 and February 2020, and 3 cases before October 2019, were selected for SARS-CoV-2 RT-PCR. Results: A statistically significant rise in pulmonary causes of death was observed in March $2020(p=0.03)$, consistent with the reported emergence of lethal COVID-19 in Switzerland. A rise in lethal bronchopneumonia was observed between December 2019 and January 2020, which was likely seasonal. The incidence of lethal ARDS and PE was uniformly low between October 2019 and February 2020. All autopsy cases analyzed by means of SARS-CoV-2 RT-PCR yielded negative results. Conclusion: Our data suggest the absence of early lethal community spread of COVID-19 in Basel before its initial reported emergence in Switzerland in March 2020.

(C) 2020 The Author(s)

Published by S. Karger AG, Basel

\section{Introduction}

We are currently in the midst of a coronavirus disease pandemic, COVID-19, caused by severe acute respiratory syndrome coronavirus 2 (SARS-CoV-2). Since the WHO karger@karger.com www.karger.com/pat

Karger $\frac{1}{\%}$

GOPEN ACCESS
(C) 2020 The Author(s)

Published by S. Karger AG, Basel

This is an Open Access article licensed under the Creative Commons Attribution-NonCommercial-4.0 International License (CC BY-NC) (http://www.karger.com/Services/OpenAccessLicense), applicable to the online version of the article only. Usage and distribution for commercial purposes requires written permission.
Alexandar Tzankov

Institute of Medical Genetics and Pathology, University Hospital Basel Schönbeinstrasse 40

$\mathrm{CH}-4031$ Basel (Switzerland)

alexandar.tzankov@usb.ch 
declared COVID-19 a pandemic on March 11, global cases have steadily risen with a total of 10.3 million cases and 508,000 deaths as of July 1,2020, out of which 31,000 cases and 1,600 deaths are attributed to Switzerland [1]. The first case of COVID-19 in Switzerland was reported on February 25, 2020, while the first lethal case was recorded on March 5, 2020 [2, 3].

SARS-CoV-2 is a part of the Orthocoronavirinae subfamily of Coronaviridae [4]. Currently, four subtypes of Orthocoronavirinae are described in the literature: while $\alpha$ - and $\beta$-coronaviruses are able to infect humans, typically causing symptoms of the common cold, $\gamma$ - and $\delta$-coronaviruses are only found in animals [5]. The zoonotic properties of coronaviruses enable host transmission from animal to human via airborne droplets [6]. Indepth studies have described a primary natural coronavirus reservoir in bats, although other secondary animal hosts include camels, mice, dogs, civet cats, ferrets, raccoons, and other rodents [7-9]. 2002 and 2012 marked key moments in our understanding of coronavirus pathogenicity, when two coronavirus outbreaks caused by severe acute respiratory syndrome coronavirus (SARS$\mathrm{CoV}$ ) and Middle-East respiratory syndrome coronavirus (MERS-CoV), respectively, developed into pandemics spreading to multiple countries and affecting thousands of individuals. In both cases, the novel virus originated from bats and spread to intermediate hosts (palm civets for SARS, camels for MERS) [10].

COVID-19 presents with similar clinical features as previous coronavirus-induced diseases, most commonly manifesting as a combination of cough, fever, and general malaise with a mean symptom onset of 14 days [11, 12]. A more serious disease progression with ICU admission was reported in a quarter of cases with a lethal disease outcome of about 10\% amongst hospitalized patients [13-15]; interestingly, this cohort reported a higher incidence of comorbid illness such as hypertension, a history of cardiovascular disease, and chronic pulmonary conditions $[16,17]$. Other suggestive predisposing features for serious disease outcome include older age $[18,19]$, obesity [20], a history of smoking [21], blood group A [22], and male sex [19]. In an effort to shed light on disease susceptibility, the scientific community is currently studying the pathophysiological complexities of lethal COVID-19, investigating the role of key players such as angiotensin-converting enzyme- 2 , a membrane protein, which has been previously shown to serve as a vital entry portal for host invasion [23-25].

Since its emergence in December 2019, a number of COVID-19 post-mortem studies have been performed.
Major histopathological findings from whole body autopsy series include diffuse alveolar damage (DAD) with superimposed bacterial pneumonia in some cases [26-29], consistent with autopsy findings from SARS and MERS [30-32]. Most strikingly, a concurrence of COVID-19 with thromboembolic events and microvascular dysfunction, a characteristic that seems to set SARS-CoV-2 apart from its coronavirus predecessors, has been observed at autopsy [26-28, 33, 34]. In one of the largest post-mortem cohorts to date, the primary cause of death was respiratory failure histologically imposing as $\mathrm{DAD}$ with extensive capillary congestion and microthrombi of pulmonary capillaries in $45 \%$ and acute pulmonary embolism (PE) in $19 \%$ of cases. Superimposed bronchopneumonia was observed in $48 \%$ and, interestingly, $28 \%$ of cases were diagnosed with senile ATTR amyloidosis upon autopsy [26]. These findings are crucial to fully understand COVID-19 pathophysiology and highlight the urgent importance of managing anticoagulation treatment, especially in patient groups with thrombosis risk factors [35].

The scope of clinical and pathological studies enables an in-depth mapping of the epidemiological dynamics and origins of COVID-19. Current evidence traces SARSCoV-2 back to the Chinese province of Hubei, where a series of pneumopathies of unknown etiology were reported in December 2019 [36]. The purported origin of the initial outbreak was a wet market in Wuhan, where close proximity between humans and a multitude of potential intermediate hosts may have facilitated host transmission [37]. However, the exact timeline of viral origins remains to be elucidated. Although Chinese authorities initially reported the emergence of the outbreak on December 31, the first case in Wuhan had shown symptoms as early as December 1 and had no direct contact to the market [12]. In view of its unspecific clinical presentation, mild disease progression, high transmissibility [38], and considerable proportion of asymptomatic cases [39, 40], unnoticed community spread before December is plausible and may have occurred; a lack of surveillance and contact tracing would have enabled the virus to spread uncontrollably to other continents. This premise is supported by a retrospective RT-PCR analysis of nasopharyngeal swabs in France, which revealed a positive case dated December 27, 1 month before the first reported case in Europe on January 24 [41, 42]. Additionally, phylogenetic analyses have revealed a high global genomic diversity of SARS-CoV-2, pointing to extensive worldwide transmission early on in the pandemic and estimating that zoonotic transfer occurred approximately between October and December 2019 [43].
96

Pathobiology 2021;88:95-105 DOI: $10.1159 / 000512563$
Haslbauer/Perrina/Matter/Dellas/ Mihatsch/Tzankov 


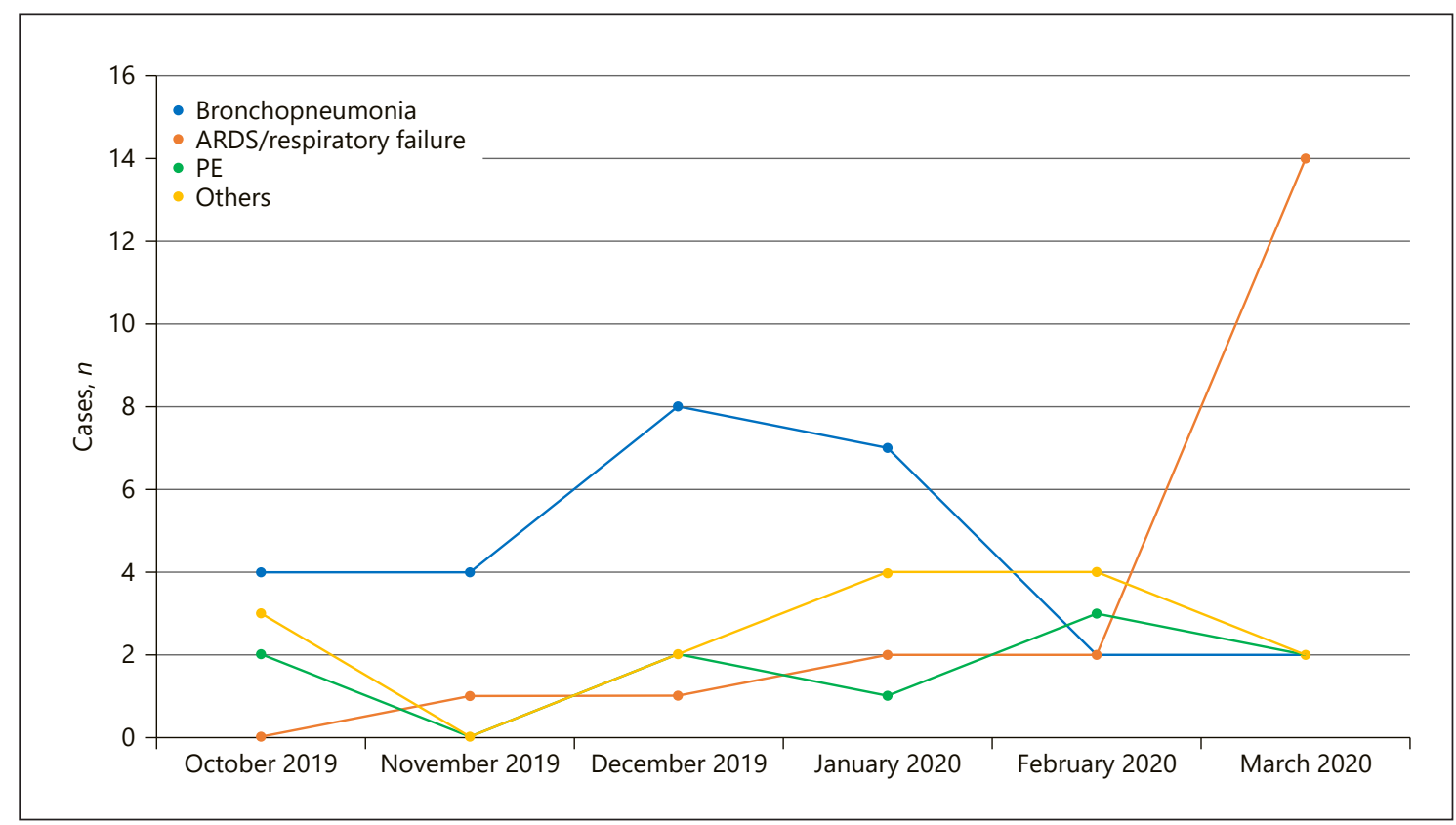

Fig. 1. Trends in pulmonary causes of death at University Hospital Basel between October 2019 and March 2020. A rise in bronchopneumonia was recorded during the months of December and January $(n=8,11.2 \% ; n=7$, $10.4 \%$, respectively), subsequently followed by a decrease in February and March. Most notably, the incidence of bronchopneumonia remained low in February and March, while there was an overwhelming increase in cases with ARDS and/or respiratory failure in March $2020(n=14,19.4 \%)$ compared to previous months. The incidence of PEs stayed constant.

Currently, evidence of early COVID-19 transmission and lethality in Central Europe is scarce. To access the presence of lethal community spread in Basel before its initial recorded emergence, we retrospectively compared the clinical cause of adult deaths at University Hospital Basel and autopsies performed at its Institute of Pathology between October 2019 and February 2020 with data from March 2020 when lethal COVID-19 was first reported in Switzerland. Autopsies with COVID-19-suggestive pathology were systematically selected for retrospective SARS-CoV-2 RT-PCR analysis.

\section{Materials and Methods}

\section{Study Cohort and Patient Selection}

A systematic retrospective analysis was performed on clinical causes of death $(n=382)$ at the University Hospital Basel and its subsidiaries between October 2019 and March 2020. In all cases, this was defined as the disease or condition leading directly to death according to the death certificate. Trends in COVID-19-suggestive sequelae, such as bronchopneumonia with organization, acute respiratory distress syndrome (ARDS), or PE were recorded (Fig. 1); trends in clinical cause of death for all cases are shown in online supplementary Figure 1 (for all online suppl. material, see www.karger.com/doi/10.1159/000512563). Next, all autopsies $(n=71)$ performed during this period at the Institute of Pathology were retrospectively analyzed. Table 1 provides an overview of the cause of death according to post-mortem report, categorized by organ system.

An in-depth study of autopsy reports and clinical history was performed on cases with a direct pulmonary cause of death between October 2019 and February $2020(n=13)$. Cases with COVID-19-suggestive sequelae were selected for retrospective RTPCR $(n=8)$. Histopathological inclusion criteria were exudative and/or proliferative DAD with or without superimposed bronchopneumonia, acute PE, thrombotic microangiopathies, cases with coagulopathies of unclear etiology, and amyloidosis. Three other cases with highly suggestive histopathological findings and disease history from an earlier period (March, June, and July 2019, respectively) also underwent RT-PCR analysis. In cases with isolated tracheobronchitis and/or bronchopneumonia with a clear microbiological etiology, exudative neutrophilic inflammation without alveolar fibrin deposition and/or perceptible thromboses of pulmonary vessels, retrospective RT-PCR was not performed. The clinical and pulmonary histology findings of selected patients are presented in Tables 2 and 3. Histological findings were analyzed independently by two pathologists (J.D.H., A.T.) on HE sections; additional immunohistochemical analyses included a fibrin stain to visualize microthrombi, and a subtypization of amyloidosis according to previously described proto- 
Table 1. Reported causes of death of adult autopsies performed at Basel University Hospital from October 2019 to March $2020(n=71)$

\begin{tabular}{|c|c|c|c|c|c|c|}
\hline Cause of death & October & November & December & January & February & March \\
\hline Cardiovascular & 5 & 1 & 5 & 4 & 2 & 6 \\
\hline Heart failure & 4 & 0 & 4 & 3 & 2 & 5 \\
\hline Myocardial infarction & 1 & 0 & 0 & 1 & 0 & 1 \\
\hline Aortic dissection & 0 & 0 & 1 & 0 & 0 & 0 \\
\hline Pulmonary & 3 & 1 & 5 & 3 & 1 & 11 \\
\hline $\mathrm{PE}$ & 1 & 0 & 2 & 1 & 0 & 0 \\
\hline Bronchopneumonia & 1 & 1 & 3 & 0 & 1 & 0 \\
\hline $\mathrm{DAD}$ & 0 & 0 & 0 & 2 & 0 & 9 \\
\hline Other & 1 & 0 & 0 & 0 & 0 & 2 \\
\hline Abdominal & 1 & 1 & 1 & 1 & 3 & 2 \\
\hline Liver failure & 0 & 0 & 1 & 0 & 0 & 0 \\
\hline Acute pancreatitis & 0 & 0 & 0 & 1 & 0 & 0 \\
\hline Abdominal hemorrhage & 0 & 0 & 0 & 0 & 1 & 0 \\
\hline Septic shock, abd. focus & 1 & 1 & 0 & 0 & 1 & 1 \\
\hline Splenic rupture & 0 & 0 & 0 & 0 & 1 & 0 \\
\hline Mesenteric ischemia & 0 & 0 & 0 & 0 & 0 & 1 \\
\hline Cerebral & 2 & 0 & 0 & 3 & 1 & 0 \\
\hline PML & 1 & 0 & 0 & 0 & 0 & 0 \\
\hline Traumatic brain injury & 1 & 0 & 0 & 0 & 0 & 0 \\
\hline Hypoxic encephalopathy & 0 & 0 & 0 & 1 & 0 & 0 \\
\hline Meningoencephalitis & 0 & 0 & 0 & 1 & 0 & 0 \\
\hline Stroke & 0 & 0 & 0 & 1 & 1 & 0 \\
\hline Terminal oncological disease & 1 & 1 & 1 & 1 & 0 & 1 \\
\hline Other & 0 & 0 & 2 & 0 & 1 & 1 \\
\hline Total autopsies performed & 12 & 4 & 14 & 12 & 8 & 21 \\
\hline
\end{tabular}

DAD, diffuse alveolar damage; PE, pulmonary embolism; PML, progressive multifocal leukoencephalopathy.

cols $[44,45]$. Pulmonary findings were either graded by means of a severity scale $(-$ no, + mild, ++ moderate, +++ extensive presence) or as a binary value (yes/no for hyaline membranes and acute PE).

\section{RT-PCR Protocol}

In respectively selected cases with COVID-19-suggestive pathology, an RT-qPCR assay for SARS-CoV-2 was performed on archived lung samples in line with the previously performed methodology [26]. RNA was extracted from formalin-fixed paraffin-embedded (FFPE) tissue using the Maxwell RSC RNA FFPE Kit (Promega, Madison, WI, USA). The TaqMan 2019-nCoV Assay Kit v1 (Thermo Fisher Scientific), which detects three separate viral genomic regions (ORFab1, S Protein, N Protein) and the human RNase P gene (RPPH1), was then employed to detect viral genomes. The viral genome copy number was quantified by a comparative CT $(\Delta \Delta \mathrm{CT})$ method using the TaqMan 2019nCoV Control Kit v1 (ThermoFisher Scientific), thus generating separate copy numbers for all genomic regions. CT values for any of the three viral genomic regions below 37 were considered positive. When CT values were between 37 and 40, the results were considered undetermined and the assay was repeated. Values above 40 were considered negative. Samples were always run in duplicates.

\section{Statistical Analysis}

Statistical analyses were performed using Microsoft Excel for Windows $2019^{\circledR}$ (Redmond, WA, USA). A Student $t$ test (independent sample with equal variance) was utilized to compare the incidence of pulmonary causes of death and its etiologies in the period before the recorded emergence of COVID-19 (October 2019 to February 2020) and March 2020 in weekly intervals. $p$ values $<0.05$ were considered significant.

\section{Results}

Trends in Clinical Causes of Death between October 2019 and March 2020

University Hospital Basel recorded 382 deaths from October 2019 to March 2020 with a peak incidence between December $2019(n=71)$ and January $2020(n=69)$; during these 2 months there was an increase of cases, which enlisted bronchopneumonia as a clinical cause of death (December $11.3 \%$, January $10.1 \%$ of deaths; Fig. 1). Twenty-seven cases (7.1\%) of lethal bronchopneumonia
98

Pathobiology 2021;88:95-105

DOI: $10.1159 / 000512563$
Haslbauer/Perrina/Matter/Dellas/ Mihatsch/Tzankov 


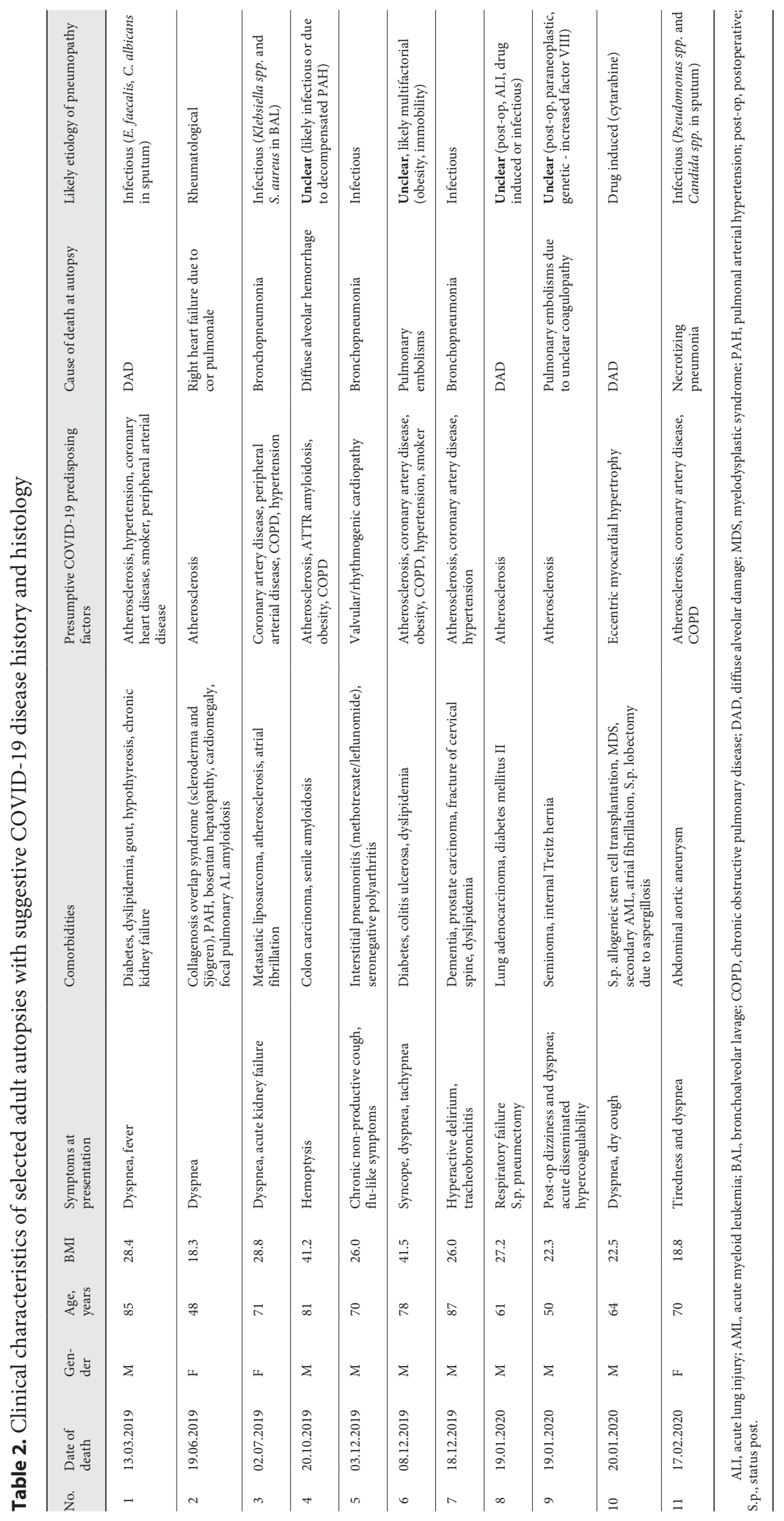




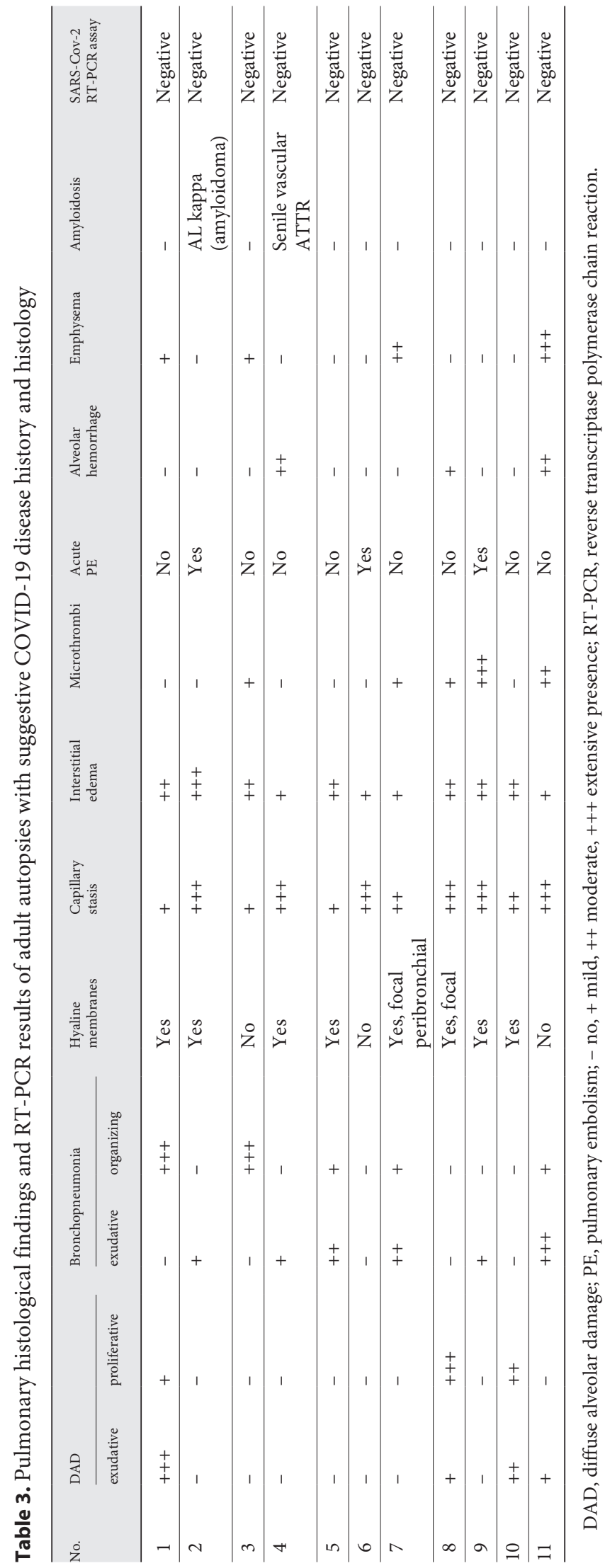

were recorded, out of which 17 cases $(63 \%)$ were $>75$ years of age upon death. The proportion of deaths caused by bronchopneumonia eventually decreased in February and March 2020. The incidence of lethal PE remained comparatively low during the examined period, while there was a sharp increase in cases with ARDS and/or respiratory failure in March $2020(p<0.05)$. When comparing the overall incidence of all deaths directly caused by a pulmonary etiology in weekly intervals, there was a statistically significant increase in pulmonary deaths in March 2020 (calendar weeks 10-14; $p=0.02$ ). A total of 13 cases in March 2020 were tested positive for SARSCoV-2 per ante-mortem nasopharyngeal swab assay. There was no overall increase in the number of deaths in March $2020(p=0.45)$.

\section{Autopsies Performed between October 2019 and March 2020}

Seventy-one autopsies were performed at the Institute of Pathology in the period investigated, with a mean autopsy rate of $15.7 \%$ between October 2019 and February 2020, which rose to 29.2\% in March 2020 (annual adult autopsy rate at University Hospital Basel in 2018: 14.5\%). Between October and February, 64\% of autopsy cases were male $(n=35)$, the overall mean age was 71 years, and the mean BMI was 27; in March 2020, 57\% of cases were male $(n=12)$, and the mean age and BMI were significantly higher (age 77 years, $p=0.015$; BMI 30, $p=0.03$ ). Table 1 represents an overview of causes of death according to post-mortem report, sorted by organ system and month. Between October and February, the most common cause of death was cardiovascular $(n=18,35 \%)$, predominantly heart failure $(n=13,26 \%)$. Twenty-five percent $(n=13)$ of deaths had a direct pulmonary cause, most commonly bronchopneumonia $(n=6,12 \%)$ and $\mathrm{PE}$ $(n=4,8 \%)$. Lethal DAD was noted in 2 cases $(4 \%)$. An unprecedented change of distribution of reported causes of death was observed in March 2020, when a sharp increase of pulmonary mortality $(n=11,52 \%)$ predominantly caused by COVID-19-induced DAD was recorded $(n=9,43 \%)$.

\section{Clinical Characteristics, Histopathological}

Findings, and RT-PCR Results of Selected Patients

with COVID-19-Suggestive Pathology

Out of the 13 cases with a direct pulmonary cause of death between October 2019 and February 2020, 8 with suggestive sequelae or microscopic findings compatible with COVID-19 were selected for retrospective SARSCoV-2 RT-PCR. Additional three autopsies with highly 


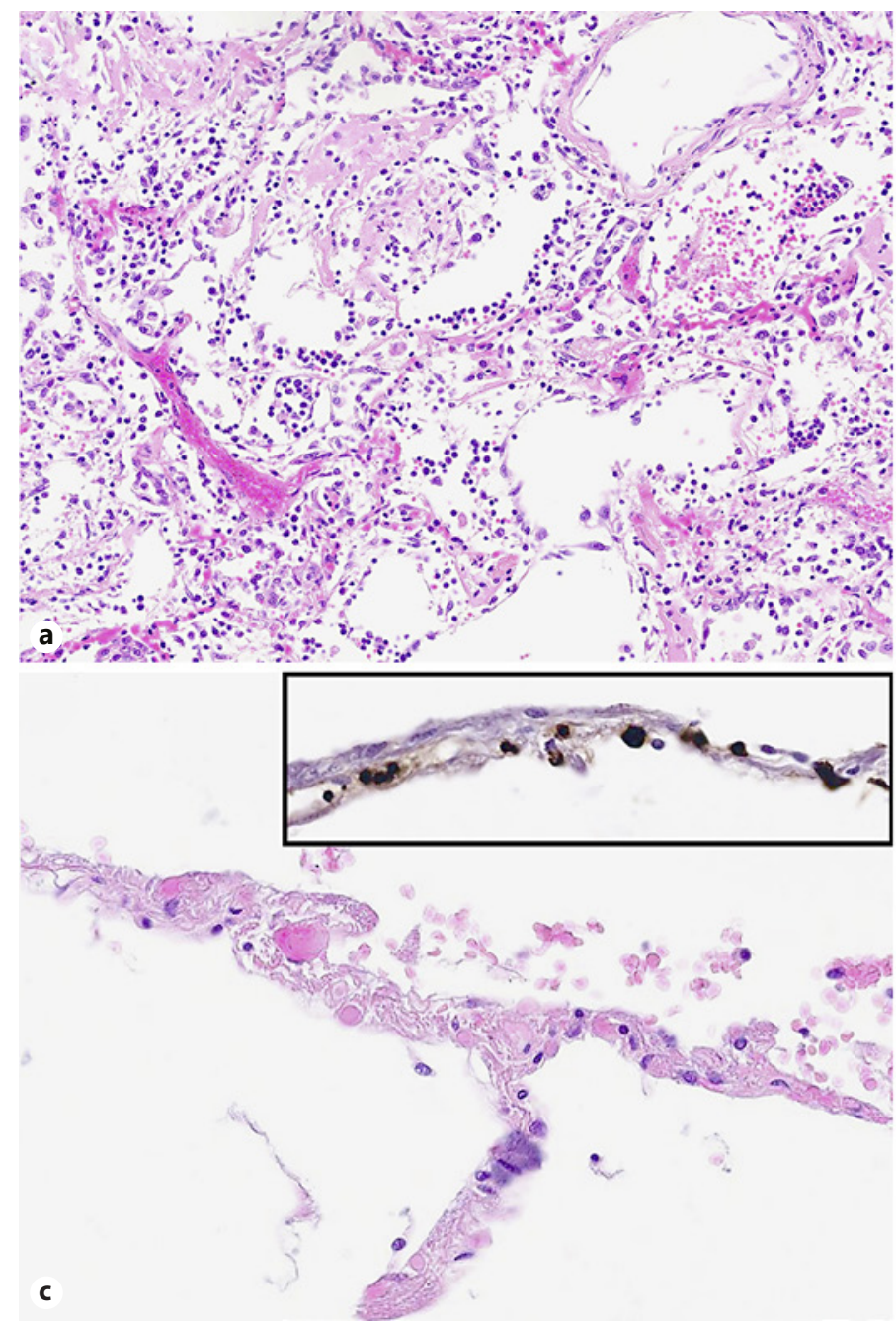

Fig. 2. Histological characteristics of COVID-19-associated DAD in comparison with DAD of other etiologies. a-c Key histological characteristics of COVID-19-associated DAD. a Exudative and proliferative $\mathrm{DAD}$ with hyaline membranes and reactive pneumocyte formation in a patient with lethal COVID-19. b Prominent capillary stasis, a hallmark of COVID-19-associated DAD. c Upon higher magnification, thrombotic occlusion can be observed in al-

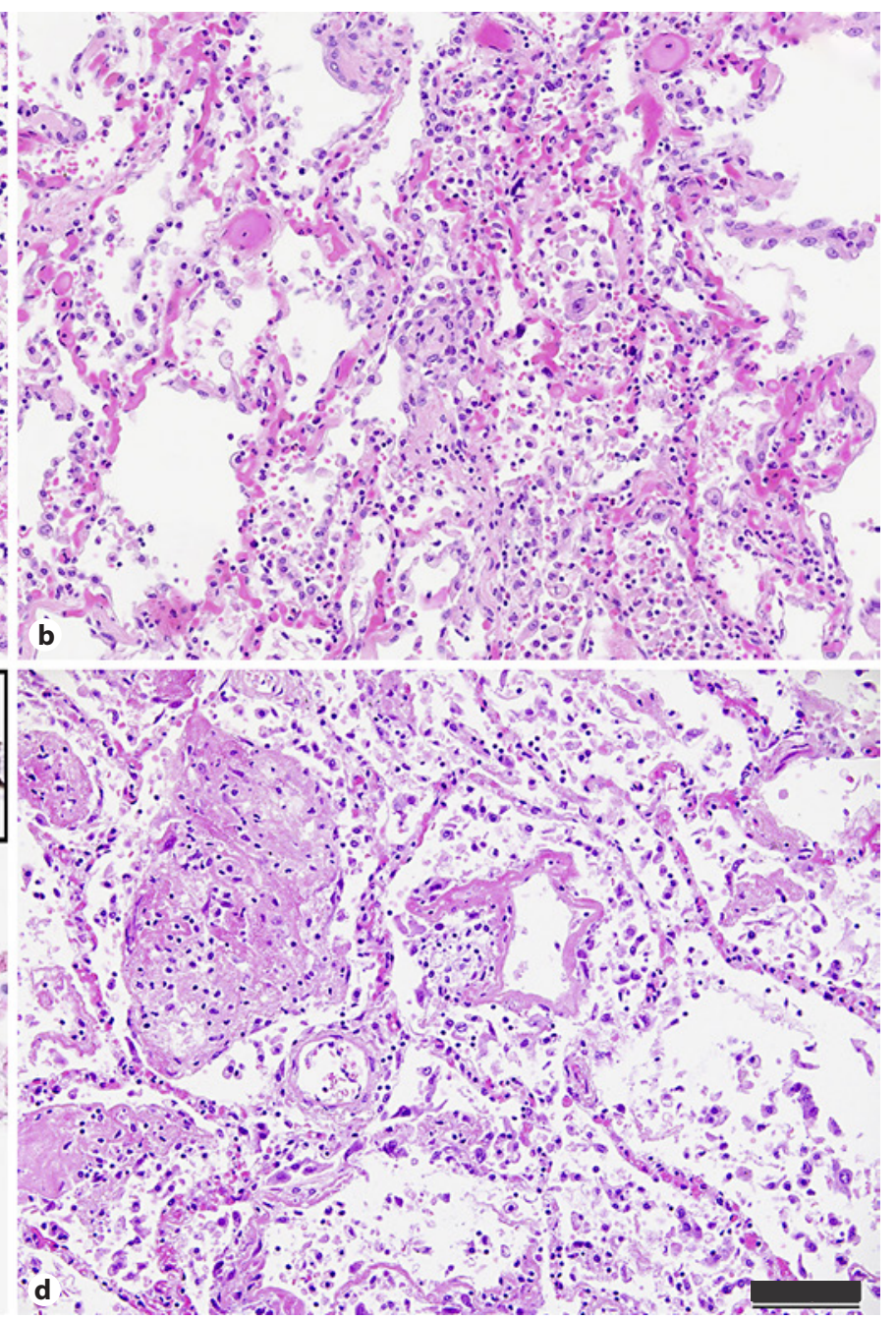

veolar capillaries. inset Immunohistochemical staining for fibrin revealed the occlusion of alveolar capillaries by microthrombi. d An exemplary representation of DAD in a COVID-19-negative patient, notably presenting with less capillary stasis and a lack of microthrombosis. The scale bar applies to $\mathbf{a}-\mathbf{d}: 100 \mu \mathrm{m}(\mathbf{a}, \mathbf{b}, \mathbf{d})$, $50 \mu \mathrm{m}(\mathbf{c})$.

was 27.4. The cause of death at autopsy was most commonly bronchopneumonia $(n=4,36.4 \%)$, followed by $\operatorname{DAD}(n=3,27.3 \%)$ and acute PE $(n=2,18.2 \%)$. Other causes of death included diffuse alveolar hemorrhage and decompensated cor pulmonale. The respective etiology of pneumopathy is presented in Table 2; in some cases the etiology was unclear, with several differential diagnoses.

Table 3 provides an overview of histological findings of the upper respiratory tract and lungs. All 3 cases with DAD presented with both exudative and proliferative
RT-PCR of COVID-19-Suggestive

Autopsies in Basel before February 2020
Pathobiology 2021;88:95-105

DOI: $10.1159 / 000512563$ 
components; in 1 case (No. 1) superimposed pneumonia was detected. All cases presented with capillary stasis and interstitial edema with varying grades of severity. One case with bronchopneumonia also presented with focal exudative DAD. Eight cases (72.7\%) presented with hyaline membrane formation and 5 cases $(45.5 \%)$ presented with microthrombi of pulmonary capillaries. RT-PCR assays performed on all cases yielded negative results.

\section{Discussion}

In this retrospective analysis of adult deaths, we aimed to investigate the presence of lethal community spread of SARS-CoV-2 in the region of Basel before its initial emergence in Switzerland in late February 2020. Systematic analysis of the clinical causes of death revealed an increase of deaths directly caused by bronchopneumonia in December 2019 and January 2020, followed by a regression of cases in February (Fig. 1). In line with previous investigations analyzing the incidence and mortality of community-acquired pneumonia and influenza-related illness during the winter months [46-49], these observations suggest a solely seasonal etiology. Seasonality typically affects older age groups [48]; 63\% of lethal bronchopneumonia in this cohort affected individuals $>75$ years of age; data which are also consistent with recent health statistics reports published by the Swiss Federal Office of Statistics [50]. Between October 2019 and February 2020, the incidence of lethal ARDS, respiratory failure and PE stayed consistently low and did not show statistically significant changes over time. The incidence of lethal PE amongst autopsies ( $n=6,8 \%$, Table 1$)$ was lower than that of a previously retrospectively investigated post-mortem cohort [51]. As ARDS and PE constitute some of the major sequelae of severe COVID-19 symptomology $[35,52]$, their underrepresentation between October and February support the absence of lethal COVID-19 during this period. Furthermore, deaths caused by other etiologies did not show any significant changes in incidence in the period investigated (online suppl. Fig. 1).

A sharp, statistically significant rise in pulmonary causes of death in March $2020(p=0.03,<0.05)$, predominantly caused by COVID-19-associated DAD (Fig. 1), was paralleled amongst autopsies conducted; $52 \%$ of autopsies conducted in March had a direct pulmonary cause of death versus $25 \%$ in the months before. This abrupt rise was accompanied by a higher autopsy rate in March (29\%) as compared to previous months. An increase of pulmonary mortality is uncharacteristic for this time of year and corresponds to the reported emergence of COVID-19 in February 2020. Interestingly, a statistically significant rise of mean age and BMI was recorded during March 2020, supporting a correlation between these factors and lethal COVID-19 as described in previously conducted post-mortem series [26, 27].

Retrospective RT-PCR case selection was performed according to suggestive clinical history as well as histological findings. The current literature does not identify defining histological characteristics of COVID-19 pathology. Rather, patterns of commonly described postmortem pulmonary findings, which are unspecific but, in combination, considered as highly suggestive for COVID-19 pneumopathy were identified and used as selection criteria for RT-PCR in this study: presence and/or a combination of DAD with severe capillary stasis with or without microthrombi, superimposed bronchopneumonia and acute PE [26-28]. The etiology of DAD is markedly heterogeneous: numerous infectious agents such as viruses and atypical pathogens such as Legionella and $M y$ coplasma spp. have been known to produce DAD, as well as drug-induced reactions, autoimmune pneumopathies, hypoperfusion, and sepsis [53]. However, SARS-CoV2 -associated DAD differs from its other etiologies in at least one aspect: while microthrombi and capillary stasis can be a feature of DAD, they are likely a histological correlate of COVID-19-associated microangiopathic disease and coagulopathy $[26,35]$. This key histological feature of COVID-19-associated DAD in comparison to its other etiologies is illustrated in Figure 2. In our cohort of retrospectively analyzed PCR cases, we have histologically observed capillary stasis in 100\% and microthrombosis in 5 out of 11 cases, in line with this specific histology (Table 3). Furthermore, post-mortem analyses have revealed an unusually high representation of vascular and interstitial amyloidosis of the heart or of the lungs in patients with lethal COVID-19 [26]. The pathophysiological aspects of this observation are currently unknown, although microangiopathic vascular amyloid deposits have previously been described in some lungs with lethal ARDS, implying an association with susceptibility to acute lung injury [54].

In our series, 3 out of 5 cases with an infectious etiology (No. 1,3, and 11) produced a positive microbiological result in sputum or bronchoalveolar lavage (Table 2). Despite these findings, SARS-CoV-2 positivity was still plausible due to the high incidence of secondary co-infections as a result of virally induced pulmonary injury, as described clinically and in previous post-mortem series 
$[26,55]$. Despite these argumentations, RT-PCR of all retrospectively analyzed samples yielded negative results for SARS-CoV-2. This implicates other likely etiologies as predominantly causative: drug-induced or postoperative for $\mathrm{DAD}$, and obesity/immobility or paraneoplastic for PE. The unclear etiology of the lethal coagulopathy in case 9 may have been due to a genetic predisposition serology revealed a pathologically high concentration of factor VIII, which increases the likelihood of thromboembolic events [56]. For a detailed discussion of all selected cases, refer to Table 2 .

Taking the latest literature into consideration, early community spread of COVID-19 is plausible due to several reasons: compared to SARS and MERS, its evolutionary dynamics suggest high human adaptability [57] in combination with a large number of asymptomatic and/ or paucisymptomatic cases $[40,58]$. SARS-CoV-2 is also more contagious than other coronaviruses; current estimates of the reproductive number $\left(\mathrm{R}_{0}\right)$ for SARS-CoV-2 lie around 1-1.5 in Switzerland [59], which is considerably higher than SARS $(0.18-1.08)$ [60] and MERS $(<1)$ [61]. This may be in part due to pre-symptomatic transmission and viral shedding after recovery, although their role in contagion is currently unclear $[62,63]$. Moreover, while phylogenic analyses suggest early widespread transmission involving many independent introductions of the virus $[43,64,65]$, they merely provide a temporal snapshot of a rapidly developing pandemic, warranting ongoing in-depth analyses and comparison of global genomic databases.

Most of the current evidence therefore suggests that early international emergence of SARS-CoV-2 in late 2019 is highly unlikely. The earliest case in the USA was reported on January 15, with evidence of limited early community spread in late January or early February [66]. A retrospective analysis of pediatric patients with influenza-related illness did not reveal the presence of COVID-19 in Italy from October 2019 to March 2020 [67]. Finally, lack of early community spread in Central Europe is also supported by the data of this study. Earlier European cases such as the one in France in December [41] are likely isolated events; in these cases, contact tracing is critical to analyze patterns of early temporal spread.

A few limitations apply to our study. Autopsy was not performed in the vast majority of deaths at University Hospital Basel (81.4\%), which limits the reliability of this analysis. Furthermore, there are several different ways to interpret a cause of death; to achieve consistent results in this study, it was defined as the most immediate condition leading to the lethal outcome, although this does not take into consideration comorbid conditions, which may have contributed to death. In addition, there is considerable discrepancy between clinical and post-mortem diagnosis, which must be kept in mind when interpreting the results of this investigation [68]. This bias was circumvented by performing a separate statistical analysis for clinical and autopsy cause of death. Moreover, the sole evaluation of deaths is not sufficient to confirm the lack of community spread - as most cases of COVID-19 are not lethal, further analyses of nasopharyngeal throat samples or serology in a study with a similar retrospective design as this one may be worth conducting. Lastly, RT-PCR was performed according to a previously established protocol at our institute, which demonstrated consistency between results in FFPE tissue and ante-mortem nasopharyngeal swabs in a cohort of 21 patients [26]. There is currently no evidence of varying sensitivity of SARS-CoV-2 RTPCR in FFPE tissue and its false-negative rate compared to detection in fresh samples; recent analyses were able to detect viral load in FFPE, even in subclinical cases [69]. Other factors, such as the post-mortem interval [70], hospitalization time, and type of treatment administered may impact RNA viability. In this respect, future studies on assay standardization are vital to increase the analytical sensitivity of RT-PCR testing.

In conclusion, the data acquired in this retrospective study support the absence of lethal community spread of SARS-CoV-2 between October 2019 and February 2020, indicating that its initial emergence in Switzerland occurred in March 2020. Further retrospective analyses are required to accurately map the timeline of COVID-19 epidemiology in Central Europe.

\section{Acknowledgements}

We would like to thank all patients included in this study and their relatives, as well as the millions of dedicated healthcare workers currently on the frontlines for their relentless effort and selflessness.

\section{Statement of Ethics}

This study received approval from the Ethics Committee of Northwestern and Central Switzerland (ID 2020-00629).

\section{Conflict of Interest Statement}

The authors have nothing to disclose.
RT-PCR of COVID-19-Suggestive

Autopsies in Basel before February 2020
Pathobiology 2021;88:95-105

DOI: $10.1159 / 000512563$ 


\section{Funding Sources}

This study was supported by the Botnar Research Centre for Child Health.

\section{Author Contributions}

Study design by M.J.M., A.D., A.T. and J.D.H. J.D.H and A.T. completed the manuscript. Histology by J.D.H., M.M. and A.T. PCR analysis by V.P. Statistics by J.D.H. All authors read and approved of the manuscript.

\section{References}

1 World Health Organization. Coronavirus Disease (COVID-19) Situation Reports [Internet]. Geneva; WHO; 2020 [cited 2020 Jul 2]. Available from: https://www.who.int/ emergencies/diseases/novel-coronavirus-2019/situation-reports.

2 Bundesamt für Gesundheit. Neues Coronavirus COVID-19. Erster bestätigter Fall in der Schweiz [Internet]. 2020 Feb 25 [cited 2020 Jun 19]. Available from: https://www.bag.admin.ch/bag/de/home/das-bag/aktuell/medienmitteilungen.msg-id-78233.html.

3 Bundesamt für Gesundheit. Neues Coronavirus: Erster Todesfall im Kanton Waadt [Internet]. 2020 Mar 3 [cited 2020 Jun 21]. Available from: https://www.bag.admin.ch/bag/ de/home/das-bag/aktuell/medienmitteilungen.msg-id-78354.html.

4 Cui J, Li F, Shi ZL. Origin and evolution of pathogenic coronaviruses. Nat Rev Microbiol. 2019 Mar;17(3):181-92.

5 Docea AO, Tsatsakis A, Albulescu D, Cristea $\mathrm{O}$, Zlatian $\mathrm{O}$, Vinceti $\mathrm{M}$, et al. A new threat from an old enemy: re-emergence of coronavirus. Int J Mol Med. 2020 Jun;45(6):1631-43.

6 Jones RM, Brosseau LM. Aerosol transmission of infectious disease. J Occup Environ Med. 2015 May;57(5):501-8.

7 Shi Z, Hu Z. A review of studies on animal reservoirs of the SARS coronavirus. Virus Res. 2008 Apr;133(1):74-87.

8 Guan Y, Zheng BJ, He YQ, Liu XL, Zhuang ZX, Cheung CL, et al. Isolation and characterization of viruses related to the SARS coronavirus from animals in southern China. Science. 2003 Oct;302(5643):276-8.

9 Latinne A, Hu B, Olival KJ, Zhu G, Zhang L, $\mathrm{Li} \mathrm{H}$, et al. Origin and cross-species transmission of bat coronaviruses in China. bioRxiv. 2020 May;2020.05.31.116061.

10 Petrosillo N, Viceconte G, Ergonul O, Ippolito G, Petersen E. COVID-19, SARS and MERS: are they closely related? Clin Microbiol Infect. 2020 Jun;26(6):729-34.

11 Li X, Wang W, Zhao X, Zai J, Zhao Q, Li Y, et al. Transmission dynamics and evolutionary history of 2019-nCoV. J Med Virol. 2020 May; 92(5):501-11.

12 Huang C, Wang Y, Li X, Ren L, Zhao J, Hu Y, et al. Clinical features of patients infected with 2019 novel coronavirus in Wuhan, China. Lancet. 2020 Feb;395(10223):497-506.

13 Chen N, Zhou M, Dong X, Qu J, Gong F, Han $\mathrm{Y}$, et al. Epidemiological and clinical characteristics of 99 cases of 2019 novel coronavirus pneumonia in Wuhan, China: a descriptive study. Lancet. 2020 Feb;395(10223):507-13.

14 Wang D, Hu B, Hu C, Zhu F, Liu X, Zhang J, et al. Clinical Characteristics of 138 Hospitalized Patients With 2019 Novel CoronavirusInfected Pneumonia in Wuhan, China. JAMA. 2020 Mar;323(11):1061-9.

15 Liu K, Fang YY, Deng Y, Liu W, Wang MF $\mathrm{Ma}$ JP, et al. Clinical characteristics of novel coronavirus cases in tertiary hospitals in $\mathrm{Hu}-$ bei Province. Chin Med J (Engl). 2020 May; 133(9):1025-31.

16 Guan WJ, Liang WH, Zhao Y, Liang HR, Chen ZS, Li YM, et al.; China Medical Treatment Expert Group for COVID-19. Comorbidity and its impact on 1590 patients with COVID-19 in China: a nationwide analysis. Eur Respir J. 2020 May;55(5):2000547.

17 Emami A, Javanmardi F, Pirbonyeh N, Akbari A. Prevalence of Underlying Diseases in Hospitalized Patients with COVID-19: a Systematic Review and Meta-Analysis. Arch Acad Emerg Med. 2020 Mar;8(1):e35. [cited 2020 Apr 16] Available from: https://www. ncbi.nlm.nih.gov/pmc/articles/ PMC7096724/

18 Liu K, Chen Y, Lin R, Han K. Clinical features of COVID-19 in elderly patients: a comparison with young and middle-aged patients. J Infect. 2020 Jun;80(6):e14-8.

19 Jin JM, Bai P, He W, Wu F, Liu XF, Han DM, et al. Gender differences in patients with COVID-19: focus on severity and mortality. Front Public Health. 2020 Apr;8:152.

20 Stefan N, Birkenfeld AL, Schulze MB, Ludwig DS. Obesity and impaired metabolic health in patients with COVID-19. Nat Rev Endocrinol. 2020 Jul;16(7):341-2.

21 van Zyl-Smit RN, Richards G, Leone FT. Tobacco smoking and COVID-19 infection. Lancet Respir Med. 2020 Jul;8(7):664-5.

$22 \mathrm{Wu} \mathrm{Y,} \mathrm{Feng} \mathrm{Z,} \mathrm{Li} \mathrm{P,} \mathrm{Yu} \mathrm{Q.} \mathrm{Relationship} \mathrm{be-}$ tween $\mathrm{ABO}$ blood group distribution and clinical characteristics in patients with $\mathrm{CO}$ VID-19. Clin Chim Acta. 2020 Oct;509:2203.

23 Imai Y, Kuba K, Rao S, Huan Y, Guo F, Guan $\mathrm{B}$, et al. Angiotensin-converting enzyme 2 protects from severe acute lung failure. $\mathrm{Na}-$ ture. 2005 Jul;436(7047):112-6.

24 Kuba K, Imai Y, Rao S, Gao H, Guo F, Guan $\mathrm{B}$, et al. A crucial role of angiotensin converting enzyme 2 (ACE2) in SARS coronavirusinduced lung injury. Nat Med. 2005 Aug; 11(8):875-9.
25 Hoffmann M, Kleine-Weber H, Schroeder S, Krüger N, Herrler T, Erichsen S, et al. SARSCoV-2 Cell Entry Depends on ACE2 and TMPRSS2 and Is Blocked by a Clinically Proven Protease Inhibitor. Cell. 2020 Apr; 181(2):271-280.e8.

26 Menter T, Haslbauer JD, Nienhold R, Savic S, Hopfer H, Deigendesch N, et al. Post-mortem examination of COVID19 patients reveals diffuse alveolar damage with severe capillary congestion and variegated findings of lungs and other organs suggesting vascular dysfunction. Histopathology. 2020 May;77(2): 198-209.

27 Wichmann D, Sperhake JP, Lütgehetmann M, Steurer S, Edler C, Heinemann A, et al. Autopsy Findings and Venous Thromboembolism in Patients With COVID-19: A Prospective Cohort Study. Ann Intern Med. 2020 Aug;173(4):268-77.

28 Lax SF, Skok K, Zechner P, Kessler HH, Kaufmann N, Koelblinger C, et al. Pulmonary arterial thrombosis in COVID-19 with fatal outcome: results from a prospective, singlecenter, clinicopathologic case series. Ann Intern Med. 2020 Sep;173(5):350-61.

29 Martines RB, Ritter JM, Matkovic E, Gary J, Bollweg BC, Bullock H, et al.; COVID-19 Pathology Working Group. Pathology and Pathogenesis of SARS-CoV-2 Associated with Fatal Coronavirus Disease, United States. Emerg Infect Dis. 2020 Sep;26(9): 2005-15.

30 Ding $Y$, Wang $H$, Shen H, Li Z, Geng J, Han $\mathrm{H}$, et al. The clinical pathology of severe acute respiratory syndrome (SARS): a report from China. J Pathol. 2003 Jul;200(3):282-9.

31 Gu J, Gong E, Zhang B, Zheng J, Gao Z, Zhong $Y$, et al. Multiple organ infection and the pathogenesis of SARS. J Exp Med. 2005 Aug; 202(3):415-24.

$32 \mathrm{Ng}$ DL, Al Hosani F, Keating MK, Gerber SI, Jones TL, Metcalfe MG, et al. Clinicopathologic, Immunohistochemical, and Ultrastructural Findings of a Fatal Case of Middle East Respiratory Syndrome Coronavirus Infection in the United Arab Emirates, April 2014. Am J Pathol. 2016 Mar;186(3):652-8.

33 Nunes Duarte-Neto A, de Almeida Monteiro RA, da Silva LF, Malheiros DM, de Oliveira EP, Theodoro Filho J, et al. Pulmonary and systemic involvement of COVID-19 assessed by ultrasound-guided minimally invasive autopsy. Histopathology. 2020 May;77(2):18697.

Haslbauer/Perrina/Matter/Dellas/ Mihatsch/Tzankov 
34 Fox SE, Akmatbekov A, Harbert JL, Li G, Quincy Brown J, Vander Heide RS. Pulmonary and cardiac pathology in African American patients with COVID-19: an autopsy series from New Orleans. Lancet Respir Med. 2020 Jul;8(7):681-6.

35 Bikdeli B, Madhavan MV, Jimenez D, Chuich T, Dreyfus I, Driggin E, et al.; Global COVID-19 Thrombosis Collaborative Group, Endorsed by the ISTH, NATF, ESVM, and the IUA, Supported by the ESC Working Group on Pulmonary Circulation and Right Ventricular Function. COVID-19 and Thrombotic or Thromboembolic Disease: Implications for Prevention, Antithrombotic Therapy, and Follow-Up: JACC State-of-the-Art Review. J Am Coll Cardiol. 2020 Jun;75(23):2950-73.

$36 \mathrm{Wu}$ F, Zhao S, Yu B, Chen YM, Wang W, Song ZG, et al. A new coronavirus associated with human respiratory disease in China. $\mathrm{Na}-$ ture. 2020 Mar;579(7798):265-9.

37 Webster RG. Wet markets-a continuing source of severe acute respiratory syndrome and influenza? Lancet. 2004 Jan;363(9404): 234-6.

38 Liu Y, Gayle AA, Wilder-Smith A, Rocklöv J. The reproductive number of COVID-19 is higher compared to SARS coronavirus. J Travel Med. 2020 Mar;27(2):taaa021.

39 Furukawa NW, Brooks JT, Sobel J. Evidence supporting transmission of severe acute respiratory syndrome coronavirus 2 while presymptomatic or asymptomatic. Emerg Infect Dis J. 2020. doi: 10.3201/eid2607.201595.

40 Mizumoto K, Kagaya K, Zarebski A, Chowell G. Estimating the asymptomatic proportion of coronavirus disease 2019 (COVID-19) cases on board the Diamond Princess cruise ship, Yokohama, Japan, 2020. Euro Surveill. 2020 Mar;25(10):2000180

41 Deslandes A, Berti V, Tandjaoui-Lambotte Y, Alloui C, Carbonnelle E, Zahar JR, et al. SARS-CoV-2 was already spreading in France in late December 2019. Int J Antimicrob Agents. 2020 Jun;55(6): 106006.

42 Spiteri G, Fielding J, Diercke M, Campese C, Enouf V, Gaymard A, et al. First cases of coronavirus disease 2019 (COVID-19) in the WHO European Region, 24 January to 21 February 2020. Euro Surveill. 2020 Mar;25(9): https://doi.org/10.2807/1560-7917. ES.2020.25.9.2000178.

43 van Dorp L, Acman M, Richard D, Shaw LP, Ford CE, Ormond L, et al. Emergence of genomic diversity and recurrent mutations in SARS-CoV-2. Infect Genet Evol. 2020 Sep;83: 104351.

44 Ehmann MA, Medinger M, Bodenmann B, Kraft S, Bollinger N, Heim D, et al. Histologic features of hematopoietic stem cell transplant-associated thrombotic microangiopathy are best percepted in deep skin biopsies and renal biopsies, while showing a significant overlap with changes related to severe acute graft-versus-host disease in gastrointestinal biopsies. Bone Marrow Transplant. 2020 Sep;55(9):1847-50.
45 Menter T, Bachmann M, Grieshaber S, Tzankov A. A More Accurate Approach to Amyloid Detection and Subtyping: Combining in situ Congo Red Staining and Immunohistochemistry. Pathobiology. 2017;84(1): 49-55.

46 Murdoch KM, Mitra B, Lambert S, Erbas B. What is the seasonal distribution of community acquired pneumonia over time? A systematic review. Australas Emerg Nurs J. 2014 Feb;17(1):30-42.

47 Lieberman D, Lieberman D, Porath A. Seasonal variation in community-acquired pneumonia. Eur Respir J. 1996 Dec;9(12): $2630-4$.

48 Crighton EJ, Moineddin R, Mamdani M, Upshur RE. Influenza and pneumonia hospitalizations in Ontario: a time-series analysis. Epidemiol Infect. 2004 Dec;132(6):1167-74.

49 Rosano A, Bella A, Gesualdo F, Acampora A, Pezzotti P, Marchetti S, et al. Investigating the impact of influenza on excess mortality in all ages in Italy during recent seasons (2013/142016/17 seasons). Int J Infect Dis. 2019 Nov; 88:127-34.

50 Bundesamt für Statistik. Gesundheitsstatistik 2019 [Internet]. 2019 Oct [cited 2020 Jun 18]. Available from: https://www.bfs.admin.ch/ bfs/de/home/aktuell/neue-veroeffentlichungen.assetdetail.10227275.html.

51 Kakkar N, Vasishta RK. Pulmonary embolism in medical patients: an autopsy-based study. Clin Appl Thromb Hemost. 2008 Apr;14(2): 159-67.

52 Rodriguez-Morales AJ, Cardona-Ospina JA, Gutiérrez-Ocampo E, Villamizar-Peña R, Holguin-Rivera Y, Escalera-Antezana JP, et al.; Latin American Network of Coronavirus Disease 2019-COVID-19 Research (LANCOVID-19). Clinical, laboratory and imaging features of COVID-19: a systematic review and meta-analysis. Travel Med Infect Dis. 2020;34:101623.

53 Beasley MB. The pathologist's approach to acute lung injury. Arch Pathol Lab Med. 2010 May;134(5):719-27.

54 Fan K, Nagle WA. Amyloid associated with elastin-staining laminar aggregates in the lungs of patients diagnosed with acute respiratory distress syndrome. BMC Pulm Med. 2002 Oct;2(1):5.

55 Cox MJ, Loman N, Bogaert D, O'Grady J. Coinfections: potentially lethal and unexplored in COVID-19. Lancet Microbe. 2020 May; 1(1):e11.

56 Kamphuisen PW, Eikenboom JC, Bertina RM. Elevated factor VIII levels and the risk of thrombosis. Arterioscler Thromb Vasc Biol. 2001 May;21(5):731-8.

57 Zhan SH, Deverman BE, Chan YA. SARSCoV-2 is well adapted for humans. What does this mean for re-emergence? bioRxiv. 2020 May; 2020.05.01.073262. https://doi.org/ $10.1101 / 2020.05 .01 .073262$
58 Tuite AR, Ng V, Rees E, Fisman D. Estimation of COVID-19 outbreak size in Italy. Lancet Infect Dis. 2020 May;20(5):537.

59 Scire J, Nadeau S, Vaughan T, Brupbacher G, Fuchs S, Sommer J, et al. Reproductive number of the COVID-19 epidemic in Switzerland with a focus on the Cantons of Basel-Stadt and Basel-Landschaft. Swiss Med Wkly. 2020(May); 150:20271.

60 Chowell G, Castillo-Chavez C, Fenimore PW, Kribs-Zaleta CM, Arriola L, Hyman JM. Model parameters and outbreak control for SARS. Emerg Infect Dis J. 2004. doi: 10.3201/ eid1007.030647.

61 Kucharski AJ, Althaus CL. The role of superspreading in Middle East respiratory syndrome coronavirus (MERS-CoV) transmission. Euro Surveill. 2015 Jun;20(25):14-8.

62 Ganyani T, Kremer C, Chen D, Torneri A, Faes C, Wallinga J, et al. Estimating the generation interval for COVID-19 based on symptom onset data. medRxiv. $2020 \mathrm{Mar}$; 2020.03.05.20031815. https://doi.org/10.1101 /2020.03.05.20031815.

63 He X, Lau EH, Wu P, Deng X, Wang J, Hao X, et al. Temporal dynamics in viral shedding and transmissibility of COVID-19. Nat Med. 2020 May;26(5):672-5.

64 Forster P, Forster L, Renfrew C, Forster M Phylogenetic network analysis of SARSCoV-2 genomes. Proc Natl Acad Sci USA. 2020 Apr;117(17):9241-3.

65 Benvenuto D, Giovanetti M, Ciccozzi A, Spoto S, Angeletti S, Ciccozzi M. The 2019-new coronavirus epidemic: evidence for virus evolution. J Med Virol. 2020 Apr;92(4):455-9.

66 Jorden MA, Rudman SL, Villarino E, Hoferka S, Patel MT, Bemis K, et al.; CDC COVID-19 Response Team. Evidence for Limited Early Spread of COVID-19 Within the United States, January-February 2020. MMWR Morb Mortal Wkly Rep. 2020 Jun;69(22):680-4.

67 Mancino E, Cristiani L, Pierangeli A, Scagnolari C, Nenna R, Petrarca L, et al. A single centre study of viral community-acquired pneumonia in children: no evidence of SARSCoV-2 from October 2019 to March 2020. J Clin Virol. 2020 Jul;128:104385.

68 Roulson J, Benbow EW, Hasleton PS. Discrepancies between clinical and autopsy diagnosis and the value of post mortem histology; a meta-analysis and review. Histopathology. 2005 Dec;47(6):551-9.

69 Guerini-Rocco E, Taormina SV, Vacirca D, Ranghiero A, Rappa A, Fumagalli C, et al. SARS-CoV-2 detection in formalin-fixed paraffin-embedded tissue specimens from surgical resection of tongue squamous cell carcinoma. J Clin Pathol. 2020 Nov;73(11):754-7.

70 Ferreira PG, Muñoz-Aguirre M, Reverter F, Sá Godinho CP, Sousa A, Amadoz A, et al. The effects of death and post-mortem cold ischemia on human tissue transcriptomes. Nat Commun. 2018 Feb;9(1):490.
RT-PCR of COVID-19-Suggestive

Autopsies in Basel before February 2020
Pathobiology 2021;88:95-105

DOI: $10.1159 / 000512563$ 